\title{
Silver nanoparticle-induced hemoglobin decrease involves alteration of histone 3 methylation status
}

\author{
Yi Qian ${ }^{\mathrm{a}, \mathrm{b}}$, Jie Zhang ${ }^{\mathrm{a}, 1}$, Qinglin $\mathrm{Hu}^{\mathrm{c}}{ }^{1}$, Ming $\mathrm{Xu}{ }^{\mathrm{a}}$, Yue Chen ${ }^{\mathrm{a}}$, Guoqing $\mathrm{Hu}^{\mathrm{c}}$, \\ Meirong Zhao ${ }^{\text {b, }{ }^{* *}, \text { Sijin Liu }}{ }^{\text {a, }}$ \\ a State Key Laboratory of Environmental Chemistry and Ecotoxicology, Research Center for Eco-Environmental Sciences, Chinese Academy of Sciences, \\ Beijing, 100085, China \\ ${ }^{\mathrm{b}}$ College of Biological and Environmental Engineering, Zhejiang University of Technology, Hangzhou, 310032, China \\ c State Key Laboratory of Nonlinear Mechanics, Beijing Key Laboratory of Engineered Construction and Mechanobiology, Institute of Mechanics, \\ Chinese Academy of Sciences, China
}

\section{A R T I C L E I N F O}

\section{Article history:}

Received 5 August 2015

Accepted 7 August 2015

Available online 11 August 2015

\section{Keywords:}

Nanosilver

Epigenetics

Transcription

Hemoglobin

Histone

Methylation

\begin{abstract}
A B S T R A C T
Silver nanoparticles (nanosilver, AgNPs) have been shown to induce toxicity in vitro and in vivo; however, the molecular bases underlying the detrimental effects have not been thoroughly understood. Although there are numerous studies on its genotoxicity, only a few studies have investigated the epigenetic changes, even less on the changes of histone modifications by AgNPs. In the current study, we probed the AgNP-induced alterations to histone methylation that could be responsible for globin reduction in erythroid cells. AgNP treatment caused a significant reduction of global methylation level for histone 3 (H3) in erythroid MEL cells at sublethal concentrations, devoid of oxidative stress. The ChIP-PCR analyses demonstrated that methylation of $\mathrm{H3}$ at lysine (Lys) 4 (H3K4) and Lys 79 (H3K79) on the $\beta$-globin locus was greatly reduced. The reduction in methylation could be attributed to decreased histone methyltransferase DOT-1L and MLL levels as well as the direct binding between AgNPs to H3/H4 that provide steric hindrance to prevent methylation as predicted by the all-atom molecular dynamics simulations. This direct interaction was further proved by AgNP-mediated pull-down assay and immunoprecipitation assay. These changes, together with decreased RNA polymerase II activity and chromatin binding at this locus, resulted in decreased hemoglobin production. By contrast, Ag ion-treated cells showed no alterations in histone methylation level. Taken together, these results showed a novel finding in which AgNPs could alter the methylation status of histone. Our study therefore opens a new avenue to study the biological effects of AgNPs at sublethal concentrations from the perspective of epigenetic mechanisms.
\end{abstract}

(c) 2015 Elsevier Ltd. All rights reserved.

\section{Introduction}

The rapid growth of nanotechnology brings great impacts on industries and many aspects of the society. Meanwhile, a wealth of studies suggest that exposure to artificial nanomaterials could incur injuries to various organisms, including health risk to humans [1-4]. To date, mounting evidence demonstrates that both metaland carbon-based nanomaterials would elicit neurotoxicity, immunotoxicity, developmental toxicity and genotoxicity [5-8]. For genotoxicity, many studies indicate that nanomaterials, such as

\footnotetext{
* Corresponding author.

** Corresponding author.

E-mail addresses: zhaomr@zjut.edu.cn (M. Zhao), sjliu@rcees.ac.cn (S. Liu).

1 Equal contribution.
}

carbon nanotubes, graphene and graphene derivatives, and silver nanoparticles (AgNPs), might lead to DNA damage by generating oxidative stress, associated with cell death [3,9]. Relative to a larger number of studies on genotoxic features of nanomaterials, only a few studies have been done to look into their capability to alter epigenetic integrity [10]. Considering the current reports on epigenetic alterations by nanomaterials, most studies were performed with focus on non-coding RNAs, such as miRNAs [10,11]. By contrast, very few studies have been carried out to assess histone modifications [10,11]. For example, gold nanoparticles and CdTe QDs were found to affect histone modifications, such as lysine methylation [12-14]. Although similar studies are still rare, these findings indicate the important contribution of histone modifications to the nanomaterial-induced biological effects.

Genetic and epigenetic mechanisms are closely intertwined, and 
feed off each other in maintaining cellular identities $[15,16]$. Epigenetic mechanisms determine the chromatin structures, and include DNA methylation, RNA modifications, histone modifications and non-coding RNAs [17]. The nucleosome, the fundamental building unit of chromatin, is made up of four histone proteins (i.e. $\mathrm{H} 2 \mathrm{~A}, \mathrm{H} 2 \mathrm{~B}, \mathrm{H} 3$ and H4). Histone modifications (mainly methylation of arginine and lysine residues) greatly affect the chromatin structure associated with the formation of active and inactive regions of the genome [18]. For instance, the lysine methylation on histone $3(\mathrm{H} 3)$ has been demonstrated to activate the gene expression on Lys4 (K4), Lys36 (K36) and Lys79 (K79) or restrain gene expression on Lys9 (K9) and Lys27 (K27) [19-21]. Disorders of epigenetic regulation would yield inappropriate repression and/or depression of certain cellular signaling pathways, likely resulting in disorders, such as cancers [22].

To ensure an accurate balance between hemoglobin production and red blood cell (RBC) formation, globin expression is fine-tuned at multiple levels including genetic and epigenetic regulation [23]. For example, the transcription of $\beta$-globin has been documented to be concertedly regulated by histone methylation on its gene locus. Transcription of $\beta$-globin was activated by increased methylation at K4 and K79 of H3 [21,24,25]. However, little is known about the influence of AgNPs on $\beta$-globin transcription through epigenetic regulations thus far. In the current study, we aimed to investigate the potential effects of AgNPs on histone modifications and relevant gene expression in erythroid cells at sublethal concentrations. Our results together demonstrated that AgNPs reduced $\beta$-globin transcription through diminishing methylation of H3K4me3 and H3K79me1 in erythroid cells, devoid of oxidative stress. This study thus unearthed a novel finding that AgNPs induced low hemoglobin count in RBCs involves alterations in histone methylation.

\section{Methods and materials}

\subsection{Characterization of AgNPs}

AgNPs with polyvinylpyrrolidone (PVP)-coating (25 nm) was purchased from Huzheng Nanotechnology Co., Ltd. (Shanghai, China). AgNP solution was freshly prepared by high-speed centrifugation $(20,000 \mathrm{~g})$ and resuspension in deionized $\mathrm{H}_{2} \mathrm{O}$ to remove $\mathrm{Ag}$ ions prior to experiments. AgNPs were characterized by transmission electron microscopy (TEM, Hitachi H7500, Japan), and the hydrodynamic diameter and zeta potential in cell culture media were determined with a Zetasizer (Malvern Nano series, Malvern, U.K.). The rate of Ag ion dissolution was carried out at different time points, as described previously [26].

\subsection{Cell culture}

Mouse erythroleukemia (MEL) cells were purchased from the Cell Resource Center of the Institute of Basic Medical Sciences (CAMS, China). MEL cells were cultured in suspension with RPMI 1640 medium (Gibco, USA) supplemented with $10 \%$ fetal bovine serum (Gibco, USA) and $2 \mathrm{mM}$-glutamine (Hyclone, USA) at $37{ }^{\circ} \mathrm{C}$ with $5 \% \mathrm{CO}_{2}$. To induce differentiation, MEL cells were cultured in the presence of $1.5 \%$ dimethylsulfoxide (DMSO, Solarbio, China) for $72 \mathrm{~h}$.

\subsection{Cytotoxicity assessment}

The cell viability was assessed by Alamar Blue assay. In brief, MEL cells were seeded into 96 -well plates with $3.0 \times 10^{4}$ cells/well. Cells were treated with AgNPs or Ag ions at a range of concentrations for $72 \mathrm{~h}$. Then, the resazurin reagent (Sigma, USA) was added into each well at a final concentration of $10 \%$ and incubated for additional $2 \mathrm{~h}$ at $37{ }^{\circ} \mathrm{C}$. Finally, the fluorescence intensity was recorded with an excitation wavelength at $530 \mathrm{~nm}$ and an emission wavelength at $590 \mathrm{~nm}$ on a microplate reader (Thermo, USA).

\subsection{Real-time $q R T-P C R$ analysis}

Total RNAs from MEL cells were isolated with Trizol according to the manufacturer's instruction (Invitrogen, USA). Mouse $\beta$-globin gene expression was determined using SYBR Green qPCR mix (Promega, USA) on an Mx3005P qRT-PCR machine (Bio-Rad, USA). Primer sequences for qRT-PCR are as following, mouse $\beta$-globin, forward: 5'-GGAAAGGTGAACGCCGATGAA-3', reverse: 5'-GGGTCCA AGGGTAGACAACC-3'; mouse GAPDH, forward: 5'-TGGCAAAGTGGAGATTGTTGCC-3', reverse: 5'-AAGATGGTGATGGGCTTCCCG-3'. GAPDH was used as an internal control.

\subsection{Molecular dynamics simulation (MDS)}

The structure of $\mathrm{H} 3-\mathrm{H} 4$ dimer is obtained from the RSCB protein data bank (ID: 1KX5) [27]. The simulation system setup and parameter settings are constructed based on the reported studies of peptide adsorption to gold nanoparticles $[28,29]$. They investigated the role of dynamics on adsorption of peptides to gold surfaces using all-atom MDS in explicit solvent. In the present study, AgNPs were built as a face-centered cubic crystal with a lattice constant of $4.0855 \AA$ As As the diameter of AgNPs ( $25 \mathrm{~nm}$ in medium) were much bigger than the size of $\mathrm{H} 3-\mathrm{H} 4$ dimer $(3-4 \mathrm{~nm})$, a flat silver surface was used. The $\mathrm{Ag}$ (001) surface was chosen and only 4 layers of atoms were considered since the van der Waals (VdW) potential was narrowly ranged. To match the experimental conditions, a saline solution was used in MDS. The size of the simulation box was $100 \times 100 \times 111 \AA^{3}$. Periodic boundary conditions were applied along all three directions. The simulations were performed using the MDS package Nanoscale Molecular Dynamics (NAMD) [30], and the CHARMM-METAL force field parameters were used [31]. The VdW interactions were modified at the distances beyond $10 \AA$ so that they smoothly became zero at $12 \AA$. The Particle-Mesh Ewald method was used for the long-rang electrostatic interactions. The $\mathrm{Ag}$ atoms were fixed through the simulations and the temperature was maintained at $295 \mathrm{~K}$ using Lowe-Andersen thermostat. The system was minimized for 4000 steps first, followed by a NPT equilibration at one atmosphere using the Langevin piston method for $700 \mathrm{ps}$ to adjust the system size in the direction perpendicular to the Ag surface. The system was then equilibrated for more than $120 \mathrm{~ns}$ in the NVT ensemble. The forces between $\mathrm{H} 3 / \mathrm{H} 4$ and $\mathrm{Ag}$ surface were calculated during the last 20 ns using the pair interaction calculation tool in NAMD. The visualization was performed using VMD [32].

\subsection{ChIP assay}

The ChIP assay was carried out with a ChIP assay Kit following the protocol from the manufacturer (Millipore, USA), with modifications for cells cultured in suspension. Briefly, MEL cells were fixed with $1 \%$ formaldehyde for $10 \mathrm{~min}$ at $37{ }^{\circ} \mathrm{C}$, and washed twice with ice-cold PBS containing 1 mM PMSF (Solarbio, Beijing, China). Then, the fixed cells were re-suspended in lysis buffer, and subjected to sonication to trim DNA into fragments with the length range from 200 to $1000 \mathrm{bp}$. After centrifugation (12,000 g for $5 \mathrm{~min}$ ), an aliquot of chromatin was saved as an input control, whereas the rest was diluted in ChIP dilution buffer. The diluted chromatin was incubated with $2 \mu \mathrm{g}$ anti-H3K4me3 antibody (Ab), anti-H3K79me1 Ab, anti-RNA polymerase II Ab, or normal IgG. Thereafter, the immunoprecipitated DNA was purified and amplified by PCR. The PCR products were separated by agarose gel electrophoresis (1\%), and 
visualized with ethidium bromide staining. The primer sequences targeting the exon2 of $\beta^{\text {maj }}$-globin gene locus for PCR are as following, forward: 5'-ACCTGACTGATGCTGAGAAGG-3', reverse: $5^{\prime}$ CCCTTGAGGCTGTCCAAGTG-3'. Quantification was performed with the software Image J (NIH, US. http://rsb.info.nih.gov/ij/). The relative level of H3K4me3, H3K79me1 and RNA polymerase II occupancy on this locus was normalized to that of their corresponding input.

\subsection{Western blotting and hemoglobin quantification}

Western blotting was performed, as previously described [26,33]. MEL cells were collected after washing with ice-cold PBS, and then lysed in RIPA lysis buffer (Solarbio, Beijing, China) containing the protease inhibitor cocktail (Roche, Switzerland). An equal amount of protein for each lysate was subjected to $10 \%$ sodium dodecyl sulfate-polyacrylamide gel electrophoresis (SDSPAGE) (Bio-Rad, USA), and then transferred to nitrocellulose membranes. Antibodies were against mouse-GAPDH (1:1000, Zhong Shan Jin Qiao, China), MLL (1:500, Santa Cruz Biotechnology, USA), DOT-1L (1:1000, Abcam, USA), H3K4me3 (1:1000, Abcam, USA), H3K79me1 (1:500, Abcam, USA), RNA polymerase II (1:1000, Sigma, USA) and Histone H3 and H4 (1:200, Bioss, China). SDSPAGE followed by coomassie blue staining was used to quantify the mass of globin concentration, as described [1,5-7]. Quantification was performed with the software Image $\mathrm{J}$.

\subsection{Pull-down assay for the binding of AgNPs to H3 and H4}

MEL cells were induced with DMSO for $72 \mathrm{~h}$, and then nuclear extracts were prepared using a nucleoprotein extraction kit (Solarbio, China). The nuclear extracts were added into the binding buffer with a final volume of $400 \mu \mathrm{L}$, as previously described [26]. Subsequently, AgNPs $(1,8 \mu \mathrm{g} / \mathrm{mL})$ or $\mathrm{Ag}$ ions $(0.8 \mu \mathrm{g} / \mathrm{mL})$ were added and incubated at $30{ }^{\circ} \mathrm{C}$ for $2 \mathrm{~h}$. After the incubation, the complexes were centrifuged at $17,000 \mathrm{~g}$ at $4{ }^{\circ} \mathrm{C}$ for $1 \mathrm{~h}$. The pellets were washed twice with ice-cold PBS, and the bound proteins were dissolved in $20 \mu \mathrm{L}$ of denaturing buffer (100 mM DTT, 5\% SDS), followed by Western blotting.

\subsection{Immunoprecipitation and inductively coupled plasma mass spectrometry (ICP-MS) analysis}

Immunoprecipitation assay was performed as described previously [26]. MEL cells were cultured in the presence of DMSO for $72 \mathrm{~h}$ with or without the treatment of AgNPs $(8 \mu \mathrm{g} / \mathrm{mL}) / \mathrm{Ag}$ ions $(0.8 \mu \mathrm{g} / \mathrm{mL})$. The nuclear extracts were prepared, and then incubated with $2 \mu$ g anti-H3, anti-H4, anti-H3K4me3, anti-H3K79me1 or normal IgG at $4{ }^{\circ} \mathrm{C}$ for overnight. Afterwards, the immunoprecipitates were collected with Gamma-Bind A Sepharose beads (GE Healthcare, UK), and the immunoprecipitated proteins were determined by Western blot assays. Thereafter, the coimmunoprecipitated AgNPs was quantified by an Agilent 7500 ICP-MS (Agilent, USA), as previously described [34].

\subsection{ROS determination}

To assess the generation of intracellular ROS, MEL cells were treated with $8 \mu \mathrm{g} / \mathrm{mL}$ AgNPs in the presence of DMSO for different times. Thereafter, $10 \mu \mathrm{M}$ 2, 7-dichlorodihydrofluorescein diacetate (DCF-DA, Sigma) was added into culture medium. After incubation for $30 \mathrm{~min}$ in the dark, cells were subjected to fluorescence detection at $525 \mathrm{~nm}$ with excitation at $488 \mathrm{~nm}$. Here, $0.1 \% \mathrm{H}_{2} \mathrm{O}_{2}$ was used as a positive control.

\subsection{Statistical analysis}

Independent $t$-test or one-way ANOVA test was used to analyze experimental data. Data were shown in mean \pm SE. In the study, statistical significance was determined with P value less than 0.05 .

\section{Results}

\subsection{Screening of sublethal concentrations of AgNPs in MEL cells}

In terms of potential risk for humans upon exposure to nanomaterials, blood cells are certainly the first line of defense against foreign particles through either biomedical applications or daily and environmental absorption. Among blood cells, RBCs are the most prominent type of cells, and damage to red cells would lead to severe disorders including various types of anemia. Thus, the study of red cell impairment upon nanomaterials treatments is highly linked to human exposure situations, and would be able to reflect potential risk for human beings under the exposure of nanomaterials. MEL cells are the erythroid precursor cells at the period proerythroblast, and can be induced to differentiate into mature red cells by DMSO [35]. Regarding $\beta$-globin, a highly expressed gene in differentiated erythroblasts, is an ideal model for the investigation of epigenetic regulation including histone methylation [18,23,36-38]. Therefore, we chose MEL cells as a model system to study the effects of AgNPs on histone methylation at the locus of $\beta$-globin gene.

Prior to cellular experiments, AgNPs were characterized thoroughly. The TEM images demonstrated that the AgNPs used here were spherical with no agglomerations, and the average diameter was $25 \mathrm{~nm}$ (Fig. 1A). The hydrodynamic diameter of AgNPs in culture medium with $10 \%$ FBS at $8 \mu \mathrm{g} / \mathrm{mL}$ was about $25 \mathrm{~nm}$ within $24 \mathrm{~h}$, and became slightly larger (approximately $30 \mathrm{~nm}$ ) at 48 and $72 \mathrm{~h}$ (Fig. 1B), indicating that AgNPs were well dispersed in culture medium. The slight increase of hydrodynamic size should be due to the formation of protein corona on AgNPs [39,40]. The zeta-potential analysis showed that AgNPs were negatively charged in culture medium over the time course (Fig. 1C), analogous to those used in our past studies [26,41]. We performed cytotoxicity screening in MEL cells treated with AgNPs at various concentrations. We deliberately made an effort to select sublethal concentrations that would not induce overt cytotoxicity to mask the subtle epigenetic changes. Here, we employed the Alamar Blue assay, which is especially suitable for cells cultured in suspension. As shown in Fig. 2A, AgNPs did not significantly reduce the viability of MEL cells until the concentration reached $12 \mu \mathrm{g} / \mathrm{mL}$, similar to our previous finding [26,41]. As a result, sublethal concentrations at $8 \mu \mathrm{g} / \mathrm{mL}$ and lower were chosen in the current study. AgNPs did not trigger ROS production at $8 \mu \mathrm{g} / \mathrm{mL}$ (Fig. 2B), in support of the results of cell viability assessment (Fig. 2A).

Since dissolved silver ions (Ag ions) play a major role in the overt toxicity induced by AgNPs [42], we looked into the likely effects from Ag ions. The measurement of particle dissolution showed that the rate of $\mathrm{Ag}$ ion release was less than $10 \%$ in culture medium for $72 \mathrm{~h}$ (Fig. 2C), consistent with our recent study [26]. For intracellular ion dissolution, our recent study also demonstrated that the majority of AgNPs stay in the form of nanoparticles with only a small portion of ion dissolution in MEL cells, evidenced by cloud point extraction for separation [26]. Here, $\mathrm{Ag}$ ions were found to have no significant toxicity to cells up to $1.2 \mu \mathrm{g} / \mathrm{mL}$ (Fig. 2D). Therefore, $\mathrm{Ag}$ ions at $0.8 \mu \mathrm{g} / \mathrm{mL}$ (referring to a concentration of the maximal ion dissolution, i.e. 10\%) were used as a control in the following experiments throughout the whole study.

\subsection{AgNPs repress expression of $\beta$-globin}

Our previous study demonstrated that the expression of $\beta$ - 
(A)
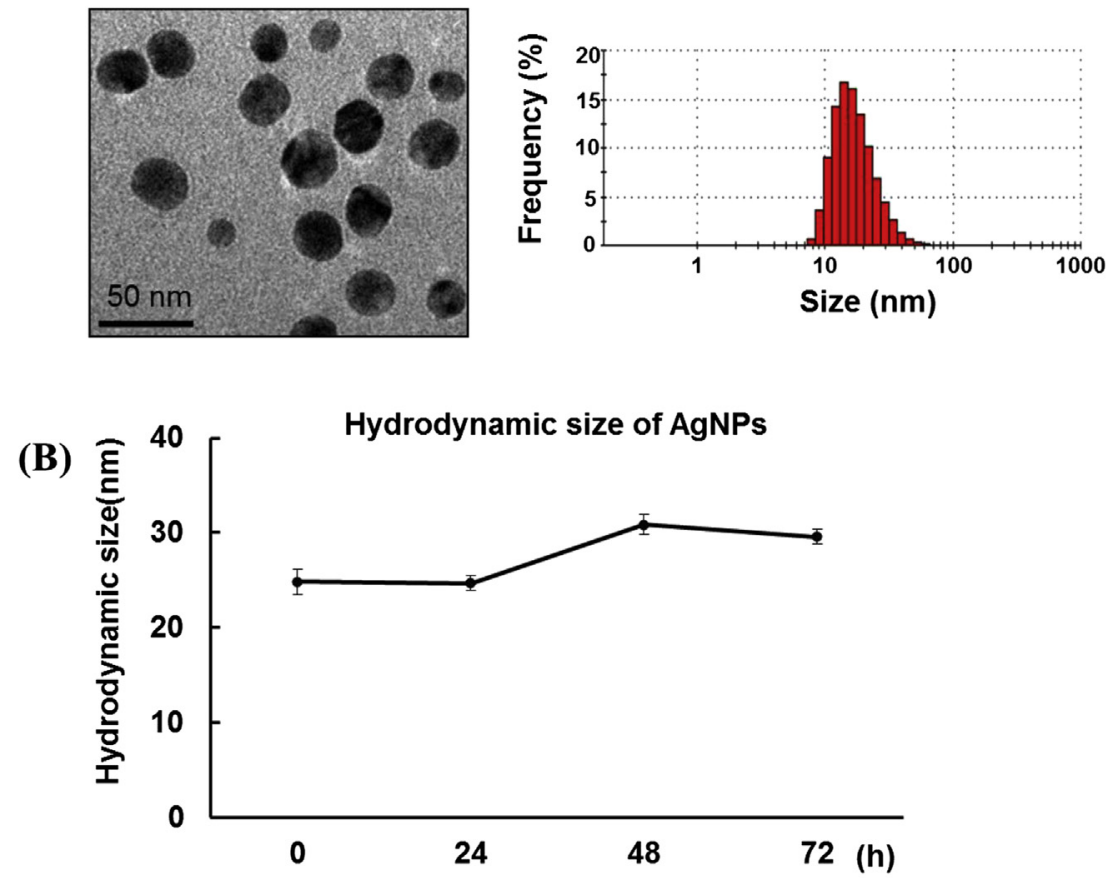

(C)

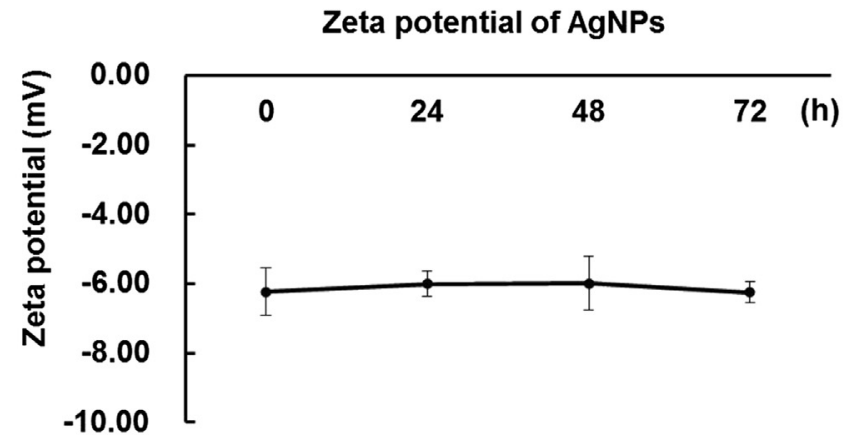

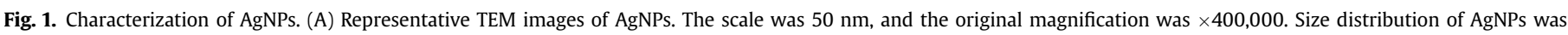

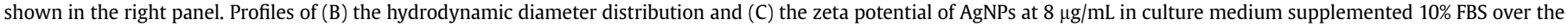
time course $(n=3)$.

globin was significantly repressed when MEL cells were treated with AgNPs post induction of differentiation for $72 \mathrm{~h}$ [26]. To interrogate whether AgNP exposure could inhibit $\beta$-globin expression within the first $72 \mathrm{~h}$ of differentiation, cells were exposed to AgNPs simultaneously with the addition of DMSO for $72 \mathrm{~h}$. The qRT-PCR analysis showed that the relative level of $\beta$ globin mRNA was reduced by approximately $20 \%$ and $50 \%$ upon AgNP treatment at 1 and $8 \mu \mathrm{g} / \mathrm{mL}$, respectively, compared to untreated cells (Fig. 3A, $\mathrm{P}<0.05$ ). Consistent with the reduction of the mRNA level, the globin protein level was also greatly reduced, evidenced by coomassie blue staining (Fig. 3B). However, Ag ions did not diminish globin content at the mRNA and protein levels (Fig. 3). Analogous to our previous data [26], these results suggested that AgNPs significantly inhibited $\beta$-globin transcription in MEL cells, and the inhibition was not found in Ag ion-treated cells.

\subsection{AgNPs reduce the global level of $\mathrm{H} 3$ methylation and histone methyltransferases}

Although the inhibition of AgNPs on globin expression was demonstrated to be mediated by an interaction between AgNPs and RNA polymerase in our previous study [26], globin gene transcription is actually regulated at multiple levels including epigenetic mechanisms [23,36]. Modification on $\mathrm{H} 3$ and $\mathrm{H} 4$ have been reported to have an important role in regulating the transcription of $\beta$-globin gene [18]. To test whether AgNP treatment could change histone modifications, we first looked into the global level of $\mathrm{H3}$ methylation through Western blotting. Since the methylation of H3K4 trimethylation (H3K4me3) and H3K79 monomethylation (H3K79me1) is highly associated with active transcription of genes, we looked at global methylation of H3K4 and H3K79 in cells upon AgNPs. As shown in Fig. 4A, the total content of H3K4me3 and H3K79me1 was diminished in AgNP-treated cells, relative to untreated cells. However, the concentration of total $\mathrm{H} 3$ did not change in cells upon AgNPs (Fig. 4A).

To look for the molecular mechanisms responsible for the global reduction of $\mathrm{H} 3$ methylation, we accessed histone methyltransferases. The myeloid/lymphoid or mixed-lineage leukemia 2 (MLL2) methyltransferase complex is crucial for H3K4 trimethylation, and is necessary for the maximal transcription of the murine 
(A)

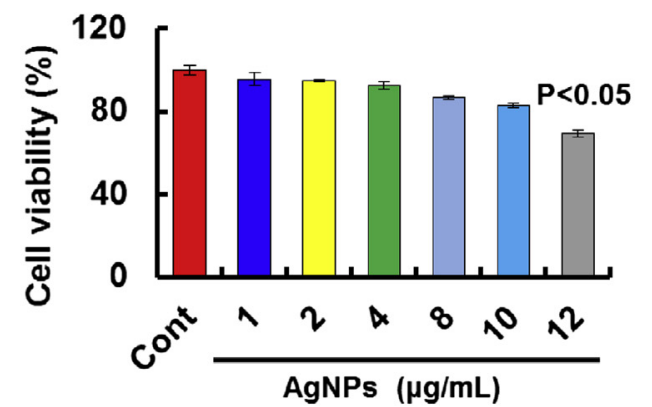

(B)

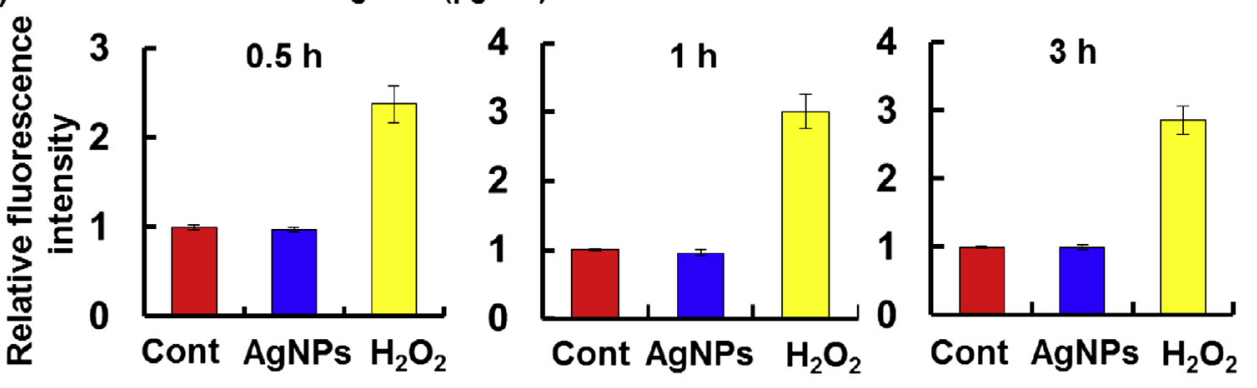

(C)

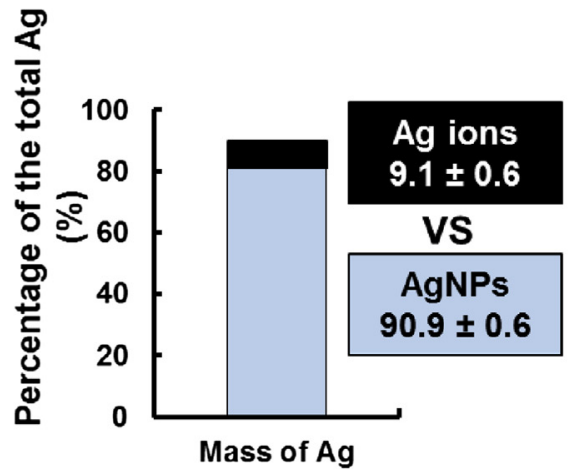

(D)

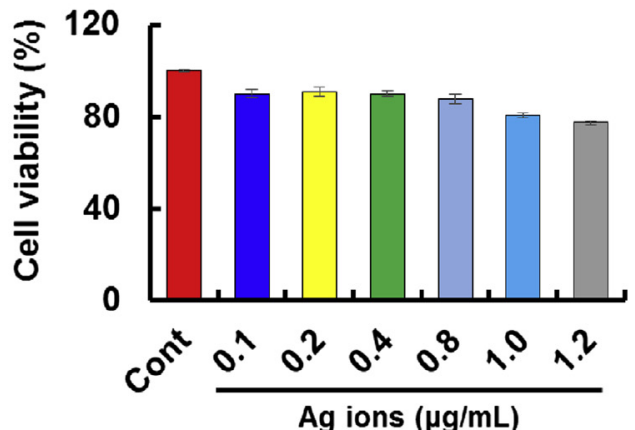

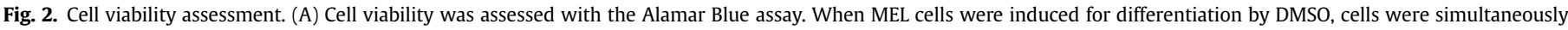

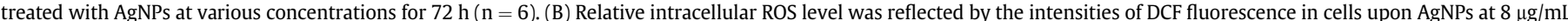

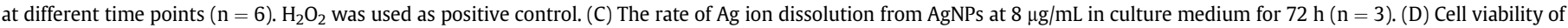

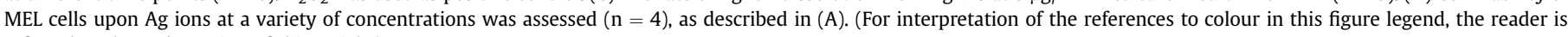
referred to the web version of this article.)

$\beta$-globin locus [24]. Similar to MLL2, disruptor of telomere silencing 1 (Dot-1L), a unique histone methyltransferase that specifically methylates $\mathrm{H} 3$ at $\mathrm{K} 79$, serves as a vital regulator of differentiation during early hematopoiesis [43]. MLL-rearranged leukemia is largely attributable to dysregulation of H3K79 methylation by Dot1L [44]. We studied the changes of histone methyltransferases, DOT-1L and MLL, specific for H3K79 and H3K4, respectively. As shown in Fig. 4B, the levels of both DOT-1L and MLL were diminished upon AgNPs, suggesting that the alteration of $\mathrm{H} 3$ methylation by AgNPs could be due to repressed histone methyltransferases.

\subsection{Reduced H3K4me3 and H3K79me1 within the $\beta$-globin locus} upon AgNPs treatment

In addition, we evaluated the level of H3K4me3 and H3K79me1 at the exon2 ( $-400 \mathrm{bp}$ downstream of the transcription state site) of the $\beta^{\text {maj }}$-globin gene transcription region within the murine $\beta$ globin locus [24] with ChIP-PCR assay. With regard to this specific type of histone modification, H3K4me3, a typical marker within $\mathrm{H} 3$ tail, correlates with transcriptional activation [25], and has been reported to have a significant role in enhancing the transcription of 
(A)

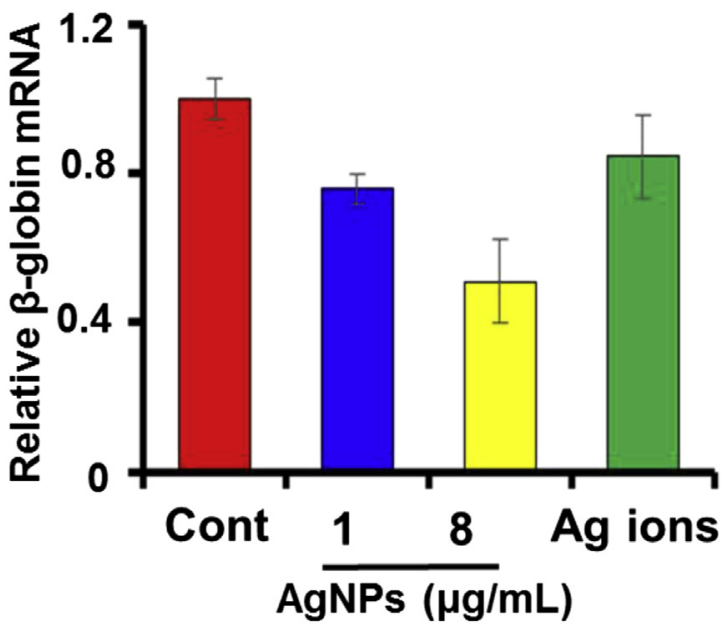

(B)

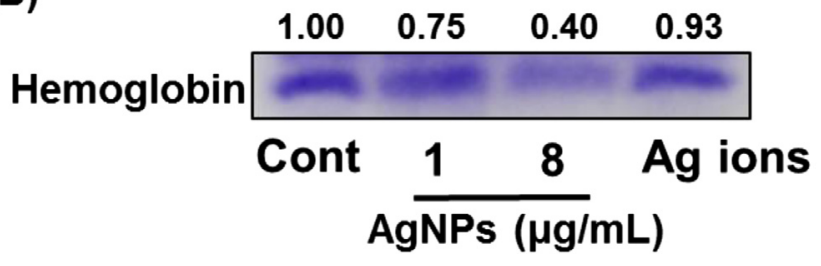

Fig. 3. Hemoglobin content upon AgNPs in MEL cells. After cells were treated with $8 \mu \mathrm{g} / \mathrm{mL} \mathrm{AgNPs}$ for $72 \mathrm{~h}$, as described in Fig. 2, an equal number of cells were collected from each group. (A) Relative expression of $\beta$-globin was measured by qRT-PCR and (B) the protein level of hemoglobin was determined by coomassie blue staining. (For interpretation of the references to colour in this figure legend, the reader is referred to the web version of this article.)

the coding region of the active $\beta^{\text {maj }}$-globin gene during erythroid differentiation for MEL cells [24]. In addition, compared to monoand dimethylation, the trimethylation of H3K4 is more associated with gene activation in vivo [45]. As demonstrated in Fig. 5A, the H3K4me3 level at the exon2 of $\beta$-globin gene locus was significantly reduced by $>50 \%$ in cells treated with $8 \mu \mathrm{g} / \mathrm{mL}$ AgNPs, relative to untreated cells. These results were in agreement with a contribution of $\mathrm{H} 3 \mathrm{~K} 4 \mathrm{me} 3$ to activate gene expression, as reduced level of H3K4me3 at $\beta$-globin locus led to a decline of $\beta$-globin expression [24].

Similar to methylation of H3K4, H3K79 is often methylated to enforce gene transcription $[21,46]$. As a marker for gene activation, H3K79me1 has a strong tie with H3K4me3 [47]. Moreover, H3K79me1 is also highly required for the activation of the coding region of the $\beta^{\text {maj }}$-globin gene [21]. The level of H3K79me1 at the exon2 of the $\beta^{\text {maj }}$-globin gene locus was also measured in cells upon AgNPs through the ChIP-PCR analysis. As shown in Fig. 5B, the ChIPPCR results showed that the level of H3K79me1 at the exon2 of the $\beta^{\text {maj }}$-globin gene locus was reduced by approximately $50 \%$ in cells treated with AgNPs, compared to untreated cells. This result was in parallel to a previous study that demonstrated that low H3K79me1 level resulted in $\beta$-globin gene repression [21].

Due to the overlaps of genomic distribution between active marks and RNA polymerase II, the methylation of H3K4 and H3K79 is highly associated with the occupancy of RNA polymerase II in driving transcription [48-50]. It would be reasonable to presume that the loss of H3K4me3 and H3K79me1 induced by AgNPs might also undermine the recruitment of RNA polymerase II. Therefore, we examined the occupancy of RNA polymerase II at the exon2 through the ChIP-PCR method. Analogous to the alterations of
(A)

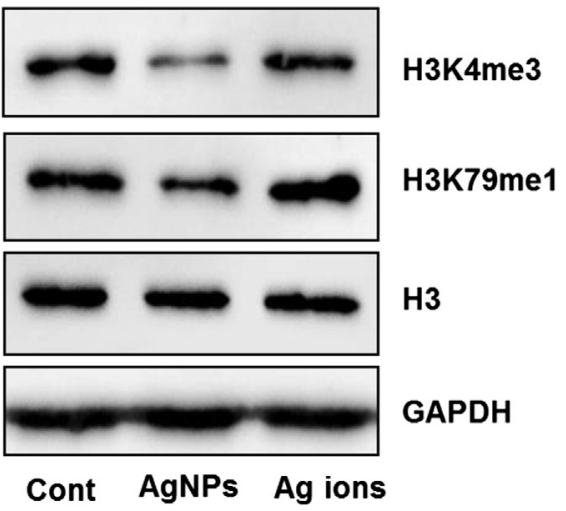

(B)

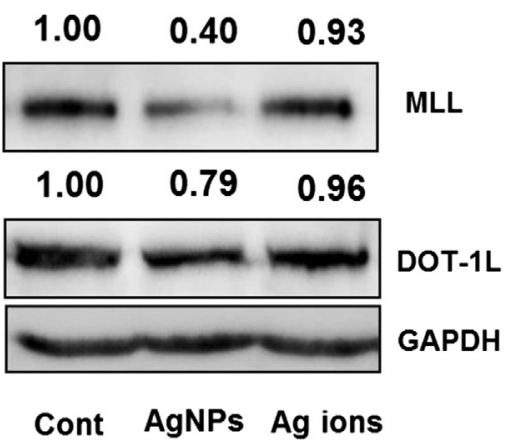

Fig. 4. Reduction of global $\mathrm{H} 3$ methylation in MEL cells upon AgNPs. MEL cells were treated with AgNPs at a concentration of $8 \mu \mathrm{g} / \mathrm{mL}$, as described in Fig. 2. (A) The global level of H3K4me3, H3K79me1 and total H3 in cells was determined by Western blotting analysis. (B) The protein concentrations of MLL and DOT-1L determined by Western blotting. GAPDH was used a loading control.

H3K4me3 and H3K79me1, the occupancy of RNA polymerase II was reduced by approximately $60 \%$ in cells treated with AgNPs, compared to untreated cells (Fig. 5C). The reduced occupancy of RNA polymerase II at the exon 2 of the $\beta^{\text {maj }}$-globin gene locus further supported the inhibited $\beta$-globin expression in AgNPtreated cells, as described above (Fig. 3). It should be stated that $\mathrm{Ag}$ ion treatment did not change the content of $\mathrm{H} 3 \mathrm{~K} 4 \mathrm{me} 3$ and H3K79me1 both at the global level and at the exon 2 of the $\beta^{\text {maj }}$ globin gene locus (Figs. 4 and 5).

\subsection{MDS indicates potential binding of AgNPs to $\mathrm{H} 3$ and $\mathrm{H} 4$}

Based on the above results, it would be reasonable to postulate an interaction of AgNPs with histone proteins. Our recent study demonstrated that AgNPs could enter nucleus in MEL cells and release Ag ions through the "Trojan horse" effects [26], and we further confirmed their nuclear localization through TEM analysis (data not shown). Thereafter, all-atom MDS was employed to investigate the possible interaction of AgNPs with histones. The interactions between $\mathrm{H} 3-\mathrm{H} 4$ dimer and $\mathrm{Ag}$ surface were simulated in a $0.154 \mathrm{M} \mathrm{NaCl}$ aqueous solution. As shown in Fig. 6A, four frames of the simulation trajectory showed that the $\mathrm{H} 3-\mathrm{H} 4$ dimer approached and directly contacted the Ag surface in solution. Visual inspection of the trajectory confirmed that the $\mathrm{H} 3-\mathrm{H} 4$ dimer was able to be strongly adsorbed and bounded to the Ag surface with the unstructured loops of $\mathrm{H} 3$ and H4 (Fig. 6A). To determine the fraction of adsorbed atoms, we considered an atom adsorbed if it is within $5 \AA$ of the silver surface. Approximately $20 \%$ of atoms of all 
(A)

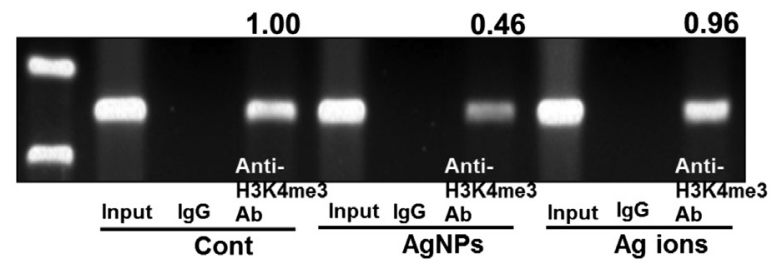

(B)

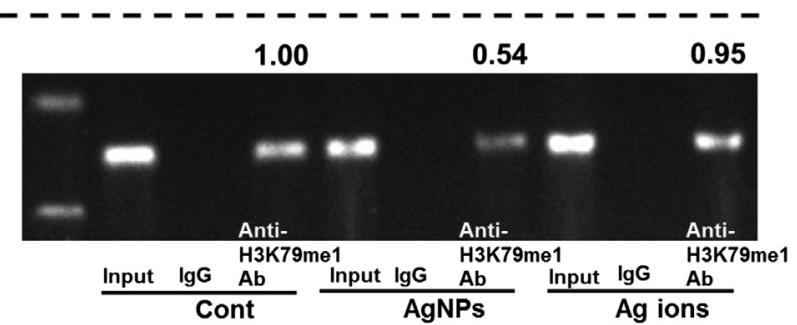

(C)

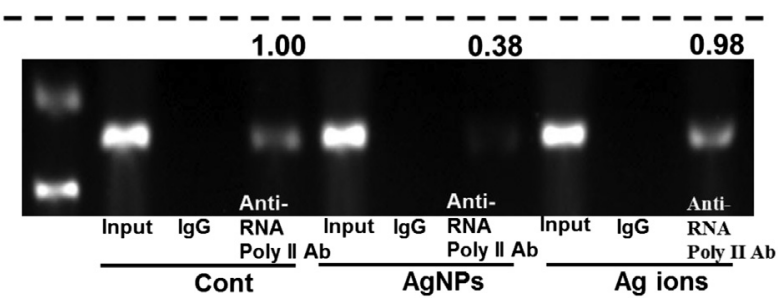

Fig. 5. Reduced $\mathrm{H} 3$ methylation at the $\beta$-globin locus in MEL cells upon AgNPs. ChIPPCR results showed the level of (A) H3K4me3 and (B) H3K79me1 at the exon2 within the $\beta$-globin locus. (C) The occupancy of RNA polymerase II was assessed at the exon 2 within the $\beta$-globin locus using ChIP-PCR analysis. Comparisons for the levels of H3K4me3, H3K79me1 and the occupancy of RNA polymerase II at the exon2 within the $\beta$-globin locus were determined relative to those in untreated cells.

types in $\mathrm{H} 3-\mathrm{H} 4$ dimer were adsorbed to the Ag surface. To quantify the strength of adsorption, the forces between the silver atoms and these two histone proteins were calculated after the adsorption became stable. As presented in Fig. 6B, the two fluctuating forces in the direction were normalized to the surface. Time-averaging forces between the silver surface and $\mathrm{H} 3$ and $\mathrm{H} 4$ were 56.87 and $20.87 \mathrm{kcal} / \mathrm{mol} / \mathrm{A}$, respectively, indicating that the $\mathrm{H} 3-\mathrm{H} 4$ dimer was able to bind to $\mathrm{Ag}$ and the strength of adsorption on $\mathrm{Ag}$ surface for $\mathrm{H} 3$ was much stronger than that for H4. Moreover, $\mathrm{H} 3$ tail rather than $\mathrm{H} 4$ was predicted to have more likelihood to interact with the Ag surface (Fig. 4). Additionally, K4 of H3 was unraveled to have closer interaction with the Ag surface than other sites (such as K79 of H3) on the basis of the simulation (Fig. 6A). Furthermore, to estimate the effect of $\mathrm{Ag}$ ions $\left(\mathrm{Ag}^{+}\right)$, we modified the system by replacing half of the sodium ions with $\mathrm{Ag}$ ions. As shown in Fig. 6C, $\mathrm{Ag}$ ions hardly affected the adsorption between the $\mathrm{H} 3-\mathrm{H} 4$ dimer and AgNP surface, and no Ag ion was adsorbed by the H3-H4 dimer while excess Ag ions went back to the AgNP surface. Together, the simulation work suggested a seeming interaction of AgNPs with $\mathrm{H} 3$ and $\mathrm{H} 4$, particularly for $\mathrm{H} 3$, and $\mathrm{Ag}$ ions could hardly bind to $\mathrm{H} 3$ or $\mathrm{H} 4$. These data also implied that the binding of AgNPs to the H3 tail may contribute to damp the methylation of H3K4 and H3K79 at the exon 2 of the $\beta$-globin gene locus, and consequentially reduce the occupancy of RNA polymerase II in this region. As the simulation study indicated, K79 was located in the loop within the globular domain of $\mathrm{H} 3$ instead of its $\mathrm{N}$-terminal tail (Fig. 6A), and we thus would assume that the core area of $\mathrm{H} 3$ (where $\mathrm{K} 79$ is in) could hardly interact with AgNPs. To this end, the low H3K79me1 level upon AgNPs could be due to the reduced level of H3K4me3 [47]; however, a direct interruption of H3K79 methylation by AgNPs could not be excluded.
(A)

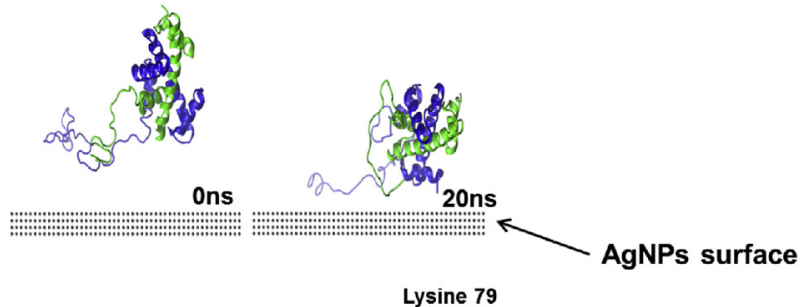

(B)

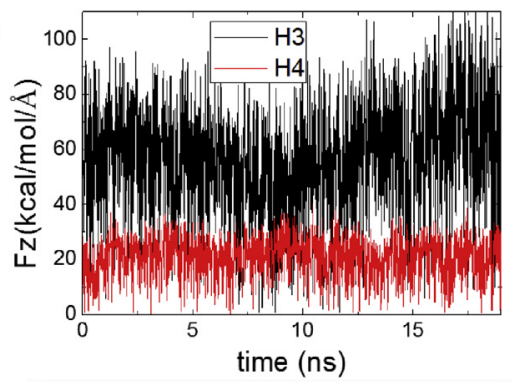

(C)
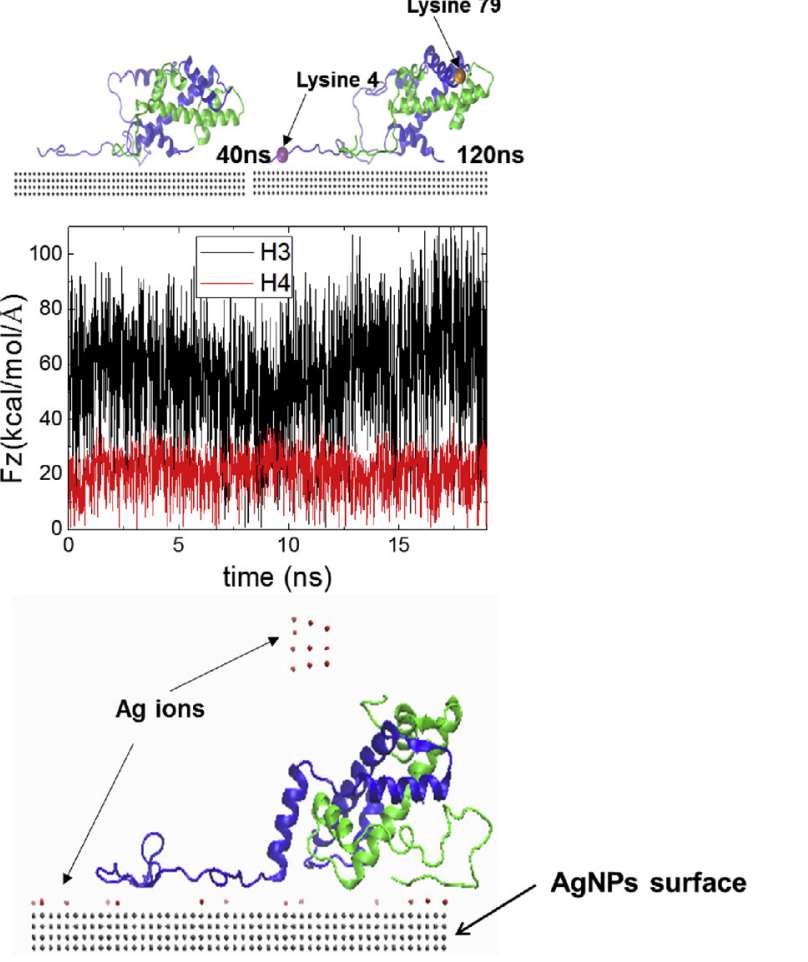

Fig. 6. Prediction analysis of interaction between $\mathrm{H} 3-\mathrm{H} 4$ dimer and $\mathrm{Ag}$ surface by MDS. (A) Snapshots of the simulation trajectory at different time points. In the last frame, alpha carbon atoms of $\mathrm{K} 4$ and $\mathrm{K} 79$ in $\mathrm{H} 3$ are shown as purple and orange spheres, respectively. For a clear view, water and ions are not drawn here. (B) Quantified data of forces along the z-direction between the Ag surface and $\mathrm{H} 3$ and $\mathrm{H} 4$ after adsorption becomes stable. (C) Snapshot of MDS system between $\mathrm{H} 3$ and $\mathrm{H} 4$ and $\mathrm{Ag}$ ions after the adsorption between the Ag surface and $\mathrm{H} 3-\mathrm{H} 4$ dimer becomes stable. $\mathrm{H} 3$ is drawn in blue with $\mathrm{H} 4$ in green, $\mathrm{Ag}$ ions in pink and $\mathrm{Ag}$ atoms of the AgNP surface in gray. Water molecules and sodium and potassium ions are not drawn for the sake of clarity.

\subsection{An active binding between AgNPs and $\mathrm{H3}$ or $\mathrm{H} 4$}

In an effort to shed light on the binding of AgNPs to histones, a pull-down assay was carried out for AgNPs in incubation with nuclear extracts from MEL cells. The Western blot assay demonstrated that $\mathrm{H} 3$ was successfully precipitated into the pellets by AgNPs at $1 \mu \mathrm{g} / \mathrm{mL}$, especially at $8 \mu \mathrm{g} / \mathrm{mL}$, with an Ab against total $\mathrm{H} 3$ (Fig. 7A). H4 was also successfully precipitated into the pellets by AgNPs at $1 \mu \mathrm{g} / \mathrm{mL}$, particularly at $8 \mu \mathrm{g} / \mathrm{mL}$, with an Ab against $\mathrm{H} 4$. However, the protein concentration of precipitated $\mathrm{H} 4$ was much less than that of $\mathrm{H3}$ (Fig. 7A and B), in agreement with the MDS results as described in Fig. 6 . The successful precipitation of $\mathrm{H} 3$ by AgNPs were also evidenced with Abs against H3K4me3 or H3K79me1 (Fig. 7C and D). Ag ions failed to precipitate either $\mathrm{H} 3$ or H4 (Fig. 7), in support of the MDS results (Fig. 6C). These findings suggested an active binding between AgNPs and histones, especially for $\mathrm{H} 3$.

To substantiate these findings, we inversely performed immunoprecipitation. As shown in Fig. 8A, H3 and H4 were successfully 
(A)

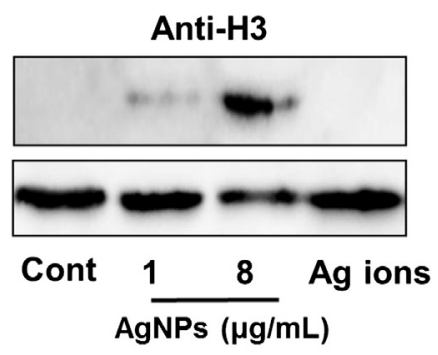

(C)

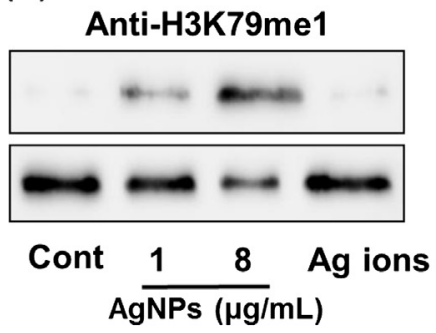

(B)

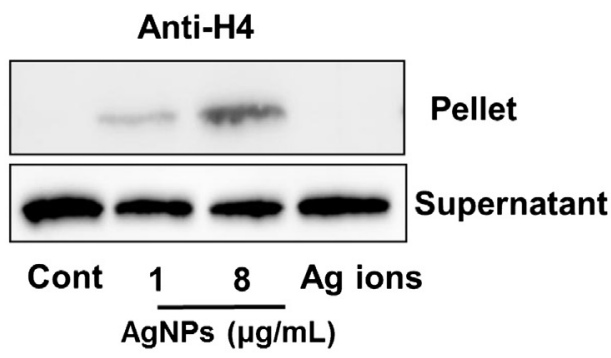

(D)

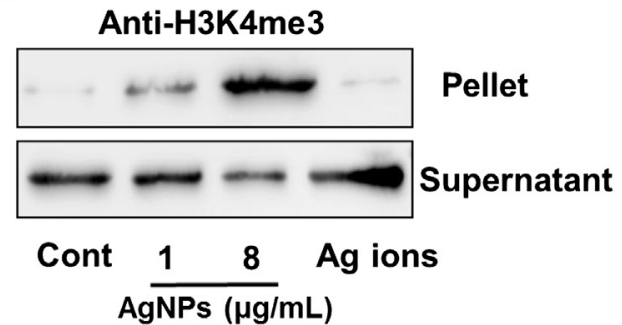

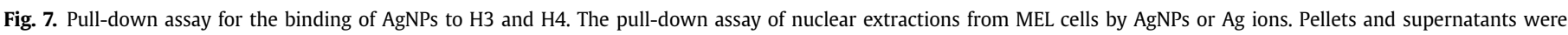
subjected to Western blotting with Abs against (A) total H3, (B) total H4, (C) H3K79me1 and (D) H3K4me3.

precipitated from the nuclear extracts in cells with or without $\mathrm{AgNP} / \mathrm{Ag}$ ions treatment by the Abs against total $\mathrm{H} 3$, total $\mathrm{H} 4$, H3K4me3 or H3K79me1. However, normal IgG failed to precipitate $\mathrm{H} 3$ and $\mathrm{H} 4$ proteins. The immunoprecipitates were then subjected to the ICP-MS analysis. Ag could be detected only in the coimmunoprecipitated nucleoproteins from AgNP-treated cells with Abs against total $\mathrm{H} 3$, total $\mathrm{H} 4$, H3K4me3 or H3K79me1 (Fig. 8B-D). A greater amount of $\mathrm{Ag}$ (over 50\%) was detected in the coimmunoprecipitated nucleoproteins by the $\mathrm{Ab}$ against total $\mathrm{H} 3$ than that by the $\mathrm{Ab}$ against total $\mathrm{H} 4$ (Fig. 8B, $\mathrm{P}<0.05$ ), indicting a stronger binding of AgNPs to $\mathrm{H} 3$ than $\mathrm{H} 4$. These data further supported the above findings on the differential binding between $\mathrm{H} 3$ and $\mathrm{H} 4$ to AgNPs (Figs. 6 and 7). No Ag could be detected in immunoprecipitated nucleoproteins from untreated cells, Ag iontreated cells or immunoprecipitated nucleoproteins with normal IgG. Thus, these results suggested an active binding of AgNPs to H3 and, to a less extent, to $\mathrm{H} 4$ inside the cells.

\section{Discussion}

Due to the antimicrobial properties, AgNPs are extensively used in a wide spectrum of fields including medicine, personal care products [51-53]. Although AgNPs offer great benefits to our lives, the large-scale applications may increase the risk to environment and human health. It should be stated that the dose of AgNPs exposed to humans is expected to be low under the environmental or daily-life setting. However, most previous studies looked into overt toxic effects of AgNPs with high-dose exposure, and did not evaluate the biological effects under sublethal exposure, which is more relevant to the real life situations [42]. Moreover, the current understanding of the mechanisms responsible for AgNP-induced cytotoxicity mainly derives from experiments with high-dose exposure, such as oxidative stress and Ag ion-mediated toxicities $[54,55]$. These mechanisms may not accurately reflect the biological effects induced by AgNPs at low doses [42]. Therefore, more attention should be paid to investigate the biological effects of AgNPs under low concentrations (at least sublethal concentrations which do not elicit significant damage to cell survival) [42]. This would help in identifying the hazards of AgNPs under the environmental and daily-life exposure settings [42]. We recently demonstrated that AgNPs could directly bind to RNA polymerase, leading to interruption of the transcription machinery and thus a drop of overall RNA synthesis in MEL cells at low concentrations without triggering detectable ROS [26]. Moreover, we demonstrated that AgNP treatment reprogrammed cellular energy homeostasis by switching from oxidative phosphorylation-based aerobic metabolism to anaerobic glycolysis in order to satisfy the basal energy demand for cell survival in both tumor cells and nontumor cells in response to sublethal AgNPs [41]. These findings highlight the potential toxicity of AgNPs to various cells at sublethal concentrations. However, whether epigenetic mechanisms (such as histone modifications) are involved in AgNP-mediated biological effects has not been investigated to date. In this study, we embarked on the effects of AgNPs on histone methylation at $\beta$ globin locus and relevant biological impacts in erythroid progenitor cells.

Histone methylation has been reported to play a crucial role in regulating both chromatin function and gene expression [56]. A number of studies have documented that the markers of gene activation, both H3K4 and H3K79 methylation, are frequently detected at the coding region of the $\beta$-globin locus during the differentiation of erythroid cells [21,57,58]. Deregulated histone modifications are implicated in various anemias (e.g. aplastic anemia), leukemias and other myelodysplastic disorders [18,59]. Histone methylation is performed by histone methyltransferases that add methyl groups to histone residues, and this process is reversed by demethylases. Thus, the methylation level of lysine in histone is determined by the net activity of histone lysine methyltransferases and demethylases $[43,60]$. Dysfunction of these enzymes would give rise to abnormal histone methylation, possibly associated with disordered gene expression and even development of various diseases [59,61,62]. However, little effort has been made to elaborate a likely disturbance of histone methylation by nanomaterials. In the current study, a significant reduction of both DOT-1L and MLL was 
(A)
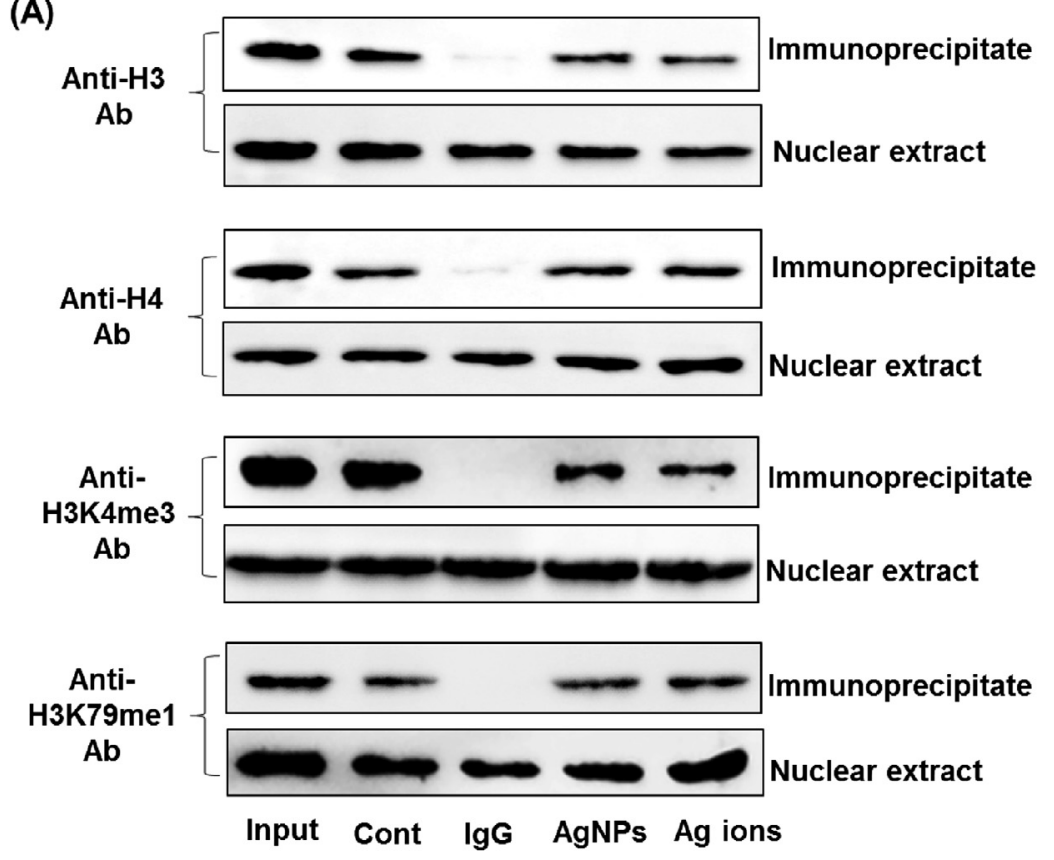

(B)

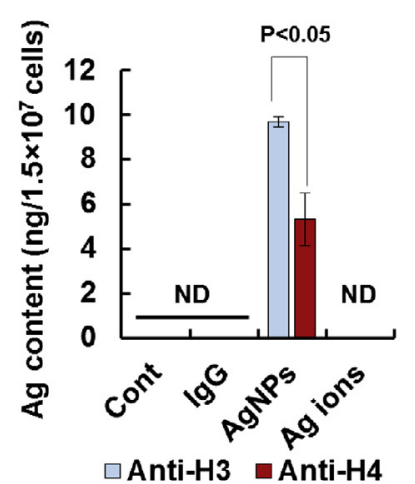

(C)

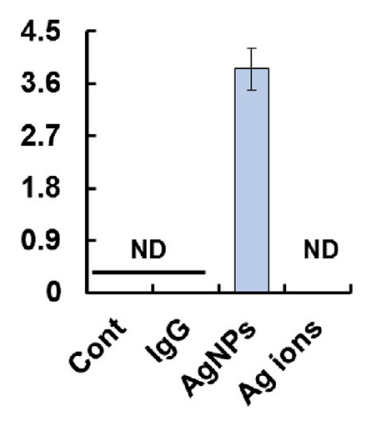

Anti-H3K4me3
(D)

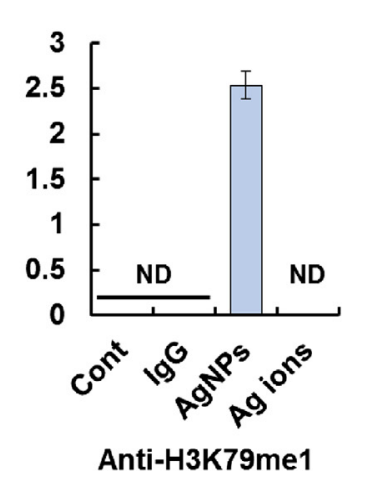

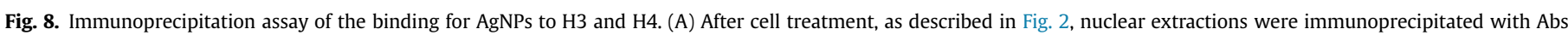

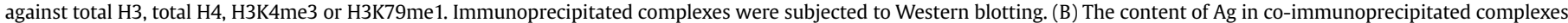

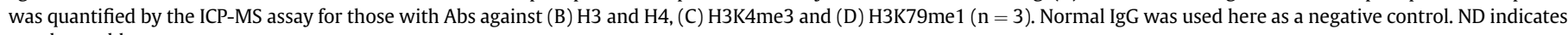
not detectable.

observed in cells treated with AgNPs. To further explore the molecular mechanisms, we used a nano-quantitative structure-activity relationship (QSAR) model, NAMD, to unveil the molecular interaction between histone and AgNPs. The theoretical simulation investigation revealed a strong interaction of AgNPs with H3. We further confirmed this interaction with AgNPmediated pull-down assay and immunoprecipitation assay. These findings thus indicated that the decline of $\mathrm{H} 3$ methylation by AgNPs could be accounted for by reduced histone methyltransferases and AgNP-histone binding-mediated steric hindrance as well. These changes together thus resulted in reduced RNA polymerase II occupancy at exon 2 of the $\beta$-globin locus and consequential downregulation of $\beta$-globin transcription.

On the other hand, our previous study has verified an interaction of AgNPs to RNA polymerase II [26], which could also explain the reduced occupancy of RNA polymerase II at $\beta$-globin locus and the consequential drop of $\beta$-globin expression. To this end, we could imagine that the overall mechanisms are rather complex, and these two mechanisms (i.e. inhibition of RNA polymerase II and H3 hypomethylation by AgNPs) are likely interwined and both are involved in AgNP-mediated suppression on globin expression. In fact, histone methylation is crucial for the efficient recruitment of RNA polymerase II, as H3K4 and H3K79 methylation promotes RNA polymerase II occupancy and H3K4 and H3K79 hypomethylation reversely inhibits RNA polymerase II occupancy [21,63,64]. However, the relative contribution of these two mechanisms to the eventual suppression of globin expression is still unclear, and further investigation therefore becomes necessary to elucidate the detailed molecular mechanisms underlying AgNP-mediated alteration to histone methylation status.

\section{Conclusions}

Although reports on the alterations of the epigenetic integrity by nanoparticles are burgeoning, little efforts have been devoted to probe the impacts of AgNPs on histone modification [10]. Only one study previously reported a particular tropism for CdTe QDs in binding to histone, although no biological impacts were assessed 
[13]. This current study unearthed that AgNPs reduced $\beta$-globin transcription through diminishing methylation of H3K4me3 and H3K79me1 in erythroid cells, devoid of intracellular oxidative stress. The molecular mechanisms involve at least, 1) the decline of histone methyltransferase DOT-1L and MLL; 2) the direct AgNPhistone binding that provides steric hindrance effects preventing methylation. These changes, along with decreased RNA polymerase II activity [26], resulted in impairment of RNA polymerase II docking to its transcription region. It should be noted that $\mathrm{Ag}$ ion-treated cells did not show changes in histone modifications; however, the role of $\mathrm{Ag}$ ions could not be completely ruled out because of intracellular presence of $\mathrm{Ag}$ ions due to the Trojan horse's effects of AgNPs [26]. These data overall signify the contribution of deregulated histone methylation by AgNPs to the development of globin deficit. Since AgNP-mediated biological effects are rather complex, histone modification changes by AgNPs could also be accounted for by other mechanisms, which warrants future investigation.

\section{Competing interests}

The authors declare no competing financial interests.

\section{Acknowledgments}

This work was supported by a grant under the National "973" program (grant number: 2014CB932000), the Strategic Priority Research Program of the Chinese Academy of Sciences (grant number. XDB14000000) and grants from the National Natural Science Foundation of China (grant numbers: 21425731, 21377159, $21321004,21207152,21407169)$. We thank all the laboratory members for their great assistance with experiments and reagents.

\section{References}

[1] C.R. Thomas, S. George, A.M. Horst, Z. Ji, R.J. Miller, J.R. Peralta-Videa, et al., Nanomaterials in the environment: from materials to high-throughput screening to organisms, ACS Nano 5 (2011) 13-20.

[2] G. Oberdorster, E. Oberdorster, J. Oberdorster, Nanotoxicology: an emerging discipline evolving from studies of ultrafine particles, Environ. Health Perspect. 113 (2005) 823-839.

[3] A. Patlolla, B. Patlolla, P. Tchounwou, Evaluation of cell viability, DNA damage and cell death in normal human dermal fibroblast cells induced by func tionalized multiwalled carbon nanotube, Mol. Cell. Biochem. 338 (2010) 225-232.

[4] M.E. Samberg, S.J. Oldenburg, N.A. Monteiro-Riviere, Evaluation of silver nanoparticle toxicity in skin in vivo and keratinocytes in vitro, Environ. Health Perspect. 118 (2010) 407-413.

[5] R. van Aerle, A. Lange, A. Moorhouse, K. Paszkiewicz, K. Ball, B.D. Johnston, et al., Molecular mechanisms of toxicity of silver nanoparticles in zebrafish embryos, Environ. Sci. Technol. 47 (2013) 8005-8014.

[6] G. Vecchio, M. Fenech, P.P. Pompa, N.H. Voelcker, Lab-on-a-chip-based highthroughput screening of the genotoxicity of engineered nanomaterials, Small 10 (2014) 2721-2734.

[7] M. Di Gioacchino, C. Petrarca, F. Lazzarin, L. Di Giampaolo, E. Sabbioni, P. Boscolo, et al., Immunotoxicity of nanoparticles, Int. J. Immunopathol. Pharmacol. 24 (2011) 65S-71S.

[8] C.M. Powers, A.S. Bale, A.D. Kraft, S.L. Makris, J. Trecki, J. Cowden, et al, Developmental neurotoxicity of engineered nanomaterials: identifying research needs to support human health risk assessment, Toxicol. Sci. Off. J. Soc. Toxicol. 134 (2013) 225-242.

[9] D. He, J.J. Dorantes-Aranda, T.D. Waite, Silver nanoparticle-algae interactions: oxidative dissolution, reactive oxygen species generation and synergistic toxic effects, Environ. Sci. Technol. 46 (2012) 8731-8738.

[10] S. Shyamasundar, C.T. Ng, L.Y. Lanry Yung, S.T. Dheen, B.H. Bay, Epigenetic mechanisms in nanomaterial-induced toxicity, Epigenomics 7 (2015) 395-411.

[11] A. Stoccoro, H.L. Karlsson, F. Coppede, L. Migliore, Epigenetic effects of nanosized materials, Toxicology 313 (2013) 3-14.

[12] C.T. Ng, S.T. Dheen, W.C. Yip, C.N. Ong, B.H. Bay, L.Y. Lanry Yung, The induction of epigenetic regulation of PROS1 gene in lung fibroblasts by gold nanoparticles and implications for potential lung injury, Biomaterials 32 (2011) $7609-7615$.

[13] J. Conroy, S.J. Byrne, Y.K. Gun'ko, Y.P. Rakovich, J.F. Donegan, A. Davies, et al., CdTe nanoparticles display tropism to core histones and histone-rich cell organelles, Small 4 (2008) 2006-2015.

[14] N. Sule, R. Singh, D.K. Srivastava, Alternative modes of binding of recombinant human histone deacetylase 8 to colloidal gold nanoparticles, J. Biomed. Nanotechnol. 4 (2008) 463-468.

[15] J.D. Choi, J.S. Lee, Interplay between epigenetics and genetics in cancer, Genomics Inform. 11 (2013) 164-173.

[16] A.B. Cherry, G.Q. Daley, Reprogramming cellular identity for regenerative medicine, Cell 148 (2012) 1110-1122.

[17] T. Kouzarides, Chromatin modifications and their function, Cell 128 (2007) 693-705.

[18] C.M. Kiefer, C. Hou, J.A. Little, A. Dean, Epigenetics of beta-globin gene regulation, Mutat. Res. 647 (2008) 68-76.

[19] A. Dean, On a chromosome far, far away: LCRs and gene expression, Trends Genet. TIG 22 (2006) 38-45.

[20] M. Lachner, R.J. O'Sullivan, T. Jenuwein, An epigenetic road map for histone lysine methylation, J. Cell Sci. 116 (2003) 2117-2124.

[21] D.J. Steger, M.I. Lefterova, L. Ying, A.J. Stonestrom, M. Schupp, D. Zhuo, et al. DOT1L/KMT4 recruitment and H3K79 methylation are ubiquitously coupled with gene transcription in mammalian cells, Mol. Cell. Biol. 28 (2008) 2825-2839.

[22] K. Ohnishi, K. Semi, Y. Yamada, Epigenetic regulation leading to induced pluripotency drives cancer development in vivo, Biochem. Biophys. Res. Commun. 455 (2014) 10-15.

[23] K.J. Hewitt, R. Sanalkumar, K.D. Johnson, S. Keles, E.H. Bresnick, Epigenetic and genetic mechanisms in red cell biology, Curr. Opin. Hematol. 21 (2014) 155-164.

[24] C. Demers, C.P. Chaturvedi, J.A. Ranish, G. Juban, P. Lai, F. Morle, et al., Activator-mediated recruitment of the MLL2 methyltransferase complex to the beta-globin locus, Mol. Cell 27 (2007) 573-584.

[25] S.M. Hattangadi, P. Wong, L. Zhang, J. Flygare, H.F. Lodish, From stem cell to red cell: regulation of erythropoiesis at multiple levels by multiple proteins, RNAs, and chromatin modifications, Blood 118 (2011) 6258-6268.

[26] Z. Wang, S. Liu, J. Ma, G. Qu, X. Wang, S. Yu, et al., Silver nanoparticles induced RNA polymerase-silver binding and RNA transcription inhibition in erythroid progenitor cells, ACS Nano 7 (2013) 4171-4186.

[27] C.A. Davey, D.F. Sargent, K. Luger, A.W. Maeder, T.J. Richmond, Solvent mediated interactions in the structure of the nucleosome core particle at $1.9 \AA$ resolution, J. Mol. Biol. 319 (2002) 1097-1113.

[28] A.V. Verde, J.M. Acres, J.K. Maranas, Investigating the specificity of peptide adsorption on gold using molecular dynamics simulations, Biomacromolecules 10 (2009) 2118-2128.

[29] A. Vila Verde, P.J. Beltramo, J.K. Maranas, Adsorption of homopolypeptides on gold investigated using atomistic molecular dynamics, Langmuir ACS J. Surf. Colloids 27 (2011) 5918-5926.

[30] J.C. Phillips, R. Braun, W. Wang, J. Gumbart, E. Tajkhorshid, E. Villa, et al., Scalable molecular dynamics with NAMD, J. Comput. Chem. 26 (2005) 1781-1802.

[31] H. Heinz, R.A. Vaia, B.L. Farmer, R.R. Naik, Accurate simulation of surfaces and interfaces of face-centered cubic metals using 12-6 and 9-6 Lennard-Jones potentials, J. Phys. Chem. C 112 (2008) 17281-17290.

[32] W. Humphrey, A. Dalke, K. Schulten, VMD: visual molecular dynamics, J. Mol. Graphics 14 (1996) 33-38.

[33] S. Zhang, Y. Chen, W. Guo, L. Yuan, D. Zhang, Y. Xu, et al., Disordered hepcidinferroportin signaling promotes breast cancer growth, Cell Signal. 26 (2014) 2539-2550.

[34] C.N. Lok, C.M. Ho, R. Chen, Q.Y. He, W.Y. Yu, H. Sun, et al., Silver nanoparticles: partial oxidation and antibacterial activities, J. Biol. Inorg. Chem. JBIC Publ. Soc. Biol. Inorg. Chem. 12 (2007) 527-534.

[35] A. Shilatifard, The COMPASS family of histone H3K4 methylases: mechanisms of regulation in development and disease pathogenesis, Annu. Rev. Biochem. 81 (2012) 65-95.

[36] A. Muller-Taubenberger, C. Bonisch, M. Furbringer, F. Wittek, S.B. Hake, The histone methyltransferase Dot1 is required for DNA damage repair and proper development in Dictyostelium, Biochem. Biophys. Res. Commun. 404 (2011) 1016-1022.

[37] J.R. Shearstone, R. Pop, C. Bock, P. Boyle, A. Meissner, M. Socolovsky, Global DNA demethylation during mouse erythropoiesis in vivo, Science 334 (2011) 799-802.

[38] R. Pop, J.R. Shearstone, O.C. Shen, Y. Liu, K. Hallstrom, M. Koulnis, et al., A key commitment step in erythropoiesis is synchronized with the cell cycle clock through mutual inhibition between PU.1 and S-phase progression, PLoS Biol. 8 (2010) pii: e1000484.

[39] C.D. Walkey, J.B. Olsen, F. Song, R. Liu, H. Guo, D.W. Olsen, et al., Protein corona fingerprinting predicts the cellular interaction of gold and silver nanoparticles, ACS Nano 8 (2014) 2439-2455.

[40] T. Miclaus, V.E. Bochenkov, R. Ogaki, K.A. Howard, D.S. Sutherland, Spatial mapping and quantification of soft and hard protein coronas at silver nanocubes, Nano Lett. 14 (2014) 2086-2093.

[41] Y. Chen, Z. Wang, M. Xu, X. Wang, R. Liu, O. Liu, et al., Nanosilver incurs an adaptive shunt of energy metabolism mode to glycolysis in tumor and nontumor cells, ACS Nano 8 (2014) 5813-5825.

[42] Z. Wang, T. Xia, S. Liu, Mechanisms of nanosilver-induced toxicological effects: more attention should be paid to its sublethal effects, Nanoscale 7 (2015) $7470-7481$.

[43] Y. Feng, Y. Yang, M.M. Ortega, J.N. Copeland, M. Zhang, J.B. Jacob, et al., Early 
mammalian erythropoiesis requires the Dot1L methyltransferase, Blood 116 (2010) 4483-4491.

[44] K.M. Bernt, N. Zhu, A.U. Sinha, S. Vempati, J. Faber, A.V. Krivtsov, et al., MLLrearranged leukemia is dependent on aberrant H3K79 methylation by DOT1L, Cancer Cell 20 (2011) 66-78.

[45] B.E. Bernstein, M. Kamal, K. Lindblad-Toh, S. Bekiranov, D.K. Bailey, D.J. Huebert, et al., Genomic maps and comparative analysis of histone modifications in human and mouse, Cell 120 (2005) 169-181.

[46] A. Pekowska, T. Benoukraf, J. Zacarias-Cabeza, M. Belhocine, F. Koch, H. Holota, et al., H3K4 tri-methylation provides an epigenetic signature of active enhancers, EMBO J. 30 (2011) 4198-4210.

[47] J.S. Lee, A. Shukla, J. Schneider, S.K. Swanson, M.P. Washburn, L. Florens, et al., Histone crosstalk between $\mathrm{H} 2 \mathrm{~B}$ monoubiquitination and $\mathrm{H} 3$ methylation mediated by COMPASS, Cell 131 (2007) 1084-1096.

[48] A. Benedikt, S. Baltruschat, B. Scholz, A. Bursen, T.N. Arrey, B. Meyer, et al., The leukemogenic AF4-MLL fusion protein causes P-TEFb kinase activation and altered epigenetic signatures, Leukemia 25 (2011) 135-144.

[49] T.A. Milne, Y. Dou, M.E. Martin, H.W. Brock, R.G. Roeder, J.L. Hess, MLL associates specifically with a subset of transcriptionally active target genes, Proc. Natl. Acad. Sci. U. S. A. 102 (2005) 14765-14770.

[50] H.H. Ng, F. Robert, R.A. Young, K. Struhl, Targeted recruitment of Set1 histone methylase by elongating Pol II provides a localized mark and memory of recent transcriptional activity, Mol. Cell 11 (2003) 709-719.

[51] X. Chen, H.J. Schluesener, Nanosilver: a nanoproduct in medical application, Toxicol. Lett. 176 (2008) 1-12.

[52] J.K. Schluesener, H.J. Schluesener, Nanosilver: application and novel aspects of toxicology, Arch. Toxicol. 87 (2013) 569-576.

[53] B. Nowack, H.F. Krug, M. Height, 120 years of nanosilver history: implications for policy makers, Environ. Sci. Technol. 45 (2011) 1177-1183.

[54] P.V. AshaRani, G. Low Kah Mun, M.P. Hande, S. Valiyaveettil, Cytotoxicity and genotoxicity of silver nanoparticles in human cells, ACS Nano 3 (2009)
$279-290$.

[55] A. Pratsinis, P. Hervella, J.C. Leroux, S.E. Pratsinis, G.A. Sotiriou, Toxicity of silver nanoparticles in macrophages, Small 9 (2013) 2576-2584.

[56] Q. Feng, H. Wang, H.H. Ng, H. Erdjument-Bromage, P. Tempst, K. Struhl, et al., Methylation of H3-lysine 79 is mediated by a new family of HMTases without a SET domain, Curr. Biol. CB 12 (2002) 1052-1058.

[57] T. Sawado, J. Halow, H. Im, T. Ragoczy, E.H. Bresnick, M.A. Bender, et al., H3 K79 dimethylation marks developmental activation of the beta-globin gene but is reduced upon LCR-mediated high-level transcription, Blood 112 (2008) 406-414.

[58] P. Wong, S.M. Hattangadi, A.W. Cheng, G.M. Frampton, R.A. Young, H.F. Lodish Gene induction and repression during terminal erythropoiesis are mediated by distinct epigenetic changes, Blood 118 (2011) E128-E138.

[59] P.A. Cloos, J. Christensen, K. Agger, K. Helin, Erasing the methyl mark: histone demethylases at the center of cellular differentiation and disease, Genes Dev. 22 (2008) 1115-1140.

[60] P.B. Rasmussen, P. Staller, The KDM5 family of histone demethylases as targets in oncology drug discovery, Epigenomics 6 (2014) 277-286.

[61] F. Crea, L. Sun, A. Mai, Y.T. Chiang, W.L. Farrar, R. Danesi, et al., The emerging role of histone lysine demethylases in prostate cancer, Mol. Cancer 11 (2012) 52.

[62] T. Suzuki, M. Terashima, S. Tange, A. Ishimura, Roles of histone methylmodifying enzymes in development and progression of cancer, Cancer Sci. 104 (2013) 795-800.

[63] A. Barski, S. Cuddapah, K. Cui, T.Y. Roh, D.E. Schones, Z. Wang, et al., Highresolution profiling of histone methylations in the human genome, Cell 129 (2007) 823-837.

[64] S.K. Kim, I. Jung, H. Lee, K. Kang, M. Kim, K. Jeong, et al., Human histone H3K79 methyltransferase DOT1L protein [corrected] binds actively transcribing RNA polymerase II to regulate gene expression, J. Biol. Chem. 287 (2012) 39698-39709. 